LICENÇA CC BY:

Artigo distribuído sob os termos

Creative Commons, permite uso e distribuição irrestrita em qualquer meio desde que o autor credite a fonte original.

\title{
A BASE NACIONAL COMUM CURRICULAR E OS SUJEITOS QUE DIRECIONAM A POLÍTICA EDUCACIONAL BRASILEIRA
}

\author{
THE NATIONAL CURRICULAR COMMON BASE AND THE SUBJECTS THAT \\ GUIDE BRAZILIAN EDUCATIONAL POLICY \\ BASE NACIONAL COMÚN CURRICULAR Y LOS SUJETOS QUE DIRIGEN LA \\ POLÍTICA EDUCATIVA BRASILEÑA
}

Maria Raquel Caetano ${ }^{1}$

${ }^{1}$ Doutora em Educação pela UFRGS. Docente do Instituto Federal Sul-RioGrandense (IFSul), Sapucaia do Sul, RS, Brasil.

\begin{abstract}
Resumo: O artigo apresenta como objetivo mapear e problematizar quem são os sujeitos que influenciaram a construção e a implementação da Base Nacional Comum Curricular (BNCC) por meio da inserção de propostas privadas no processo. A BNCC é uma demanda da Lei de Diretrizes e Bases da Educação Nacional e uma agenda do Plano Nacional de Educação. Em 2013, surge o Movimento pela Base Nacional Comum coordenado e financiado pela Fundação Lemann, entre outros, orientando a política educacional brasileira, trazendo consequências para o conteúdo educacional.
\end{abstract}

Palavras-chave: BNCC; Sujeitos; Público-privado.

Abstract: The article enquires into, and maps the subjects that have influenced the construction and implementation of the National Curricular Common Base (BNCC) through the insertion of private proposals in the process. The BNCC is a demand of the Law of National Education Guidelines and Bases and an agenda of the National Education Plan. In 2013, the Movement for the Common National Base was coordinated and financed by the Lemann Foundation, among others, to guide Brazilian educational policy, bringing consequences for educational content.

Keywords: BNCC; Subjects; Public-private.

Resumen: El artículo presenta como objetivo mapear y problematizar quiénes son los sujetos que influenciaron en la construcción e implementación de la Base Nacional Común Curricular (BNCC) a través de la inserción de propuestas privadas en el proceso. La BNCC es una demanda de la Ley de Directrices y Bases de la Educación Nacional y una agenda del Plan Nacional de Educación. En 2013 surge el Movimiento por la Base Nacional Común coordinado y financiado por la Fundación Lemann, entre otros, orientando la política educativa brasileña trayendo consecuencias para el contenido educativo.

Palabras clave: BNCC; Sujetos; Público-privado. 


\section{Introdução}

No contexto do capitalismo atual, as reformas na gestão pública bem como as reformas educacionais propõem alterar as estruturas da escola, promovendo mudanças administrativas e pedagógicas com a implantação de uma gestão educacional apoiada no modelo empresarial, as quais são orientadas pelos princípios gerenciais. A ênfase dada à gestão gerencial na educação deve ser analisada na construção do discurso de que a qualidade na educação depende da eficiência e da eficácia do sistema público de ensino representado por meio dos resultados e da alteração na lógica da gestão da educação. A falta de produtividade da escola (FRIGOTTO, 2010) vem alicerçando as justificativas para a expansão do setor privado e do terceiro setor mercantil, mediando a produtividade para o mercado e introduzindo formas de privatização da escola pública. O parâmetro de qualidade passa a ser o mercado. Por terceiro setor mercantil, entendemos as instituições como fundações e institutos que operam a partir de ferramentas gerenciais e estão ligadas de alguma forma ao mercado, como bancos, instituições financeiras, entre outros que influenciam por meio de suas propostas a educação pública. Essas propostas podem ser programas, plataformas digitais, modelos de gestão, consultorias.

As diferentes manifestações da privatização da educação pública se tornam uma prática de gestão adotada pelos sistemas públicos para imprimirem uma suposta qualidade na educação sob a ótica dos resultados. Para isso, utilizam-se de diversas estratégias, entre elas os contratos de gestão, termos de cooperação, parcerias públicoprivadas (PPP), que formam "quase-mercados", em que a propriedade permanece pública, mas o conteúdo da gestão é privado.

A privatização, a terceirização, a descentralização e a publicização são estratégias gerenciais consideradas modernizadoras presentes na proposta de Reforma do Estado para diminuir o papel do Estado perante as políticas sociais e a educação pública, que se situam no marco referencial dos organismos multilaterais, especialmente do Banco Mundial, propiciando os quase-mercados. Nossas análises partem da compreensão de que a privatização da educação está inserida em um movimento mundial econômicopolítico e social, em que a crise do capital é o centro e que o capital se organiza e reorganiza em várias esferas da vida social. Se por um lado as propostas privatistas em relação à educação avançam; por outro, há movimentos conservadores que vêm influenciando as agendas educacionais. Nesse artigo abordaremos as propostas privatistas que influenciam diretamente a política educacional, como é o caso da BNCC. As tendências à privatização estão tendo maior ou menor influência nos diferentes países e se concretizam de diferentes formas nos sistemas de educação pública.

No Brasil, o Relatório sobre Privatização da Educação na América Latina e Caribe (2012) aponta a atuação do terceiro setor e a presença de negócios transnacionais ligados a setores financeiros e privados tradicionais do país. 
Nesse contexto, inserem-se os estudos já realizados no Brasil por Adrião (2014), Peroni (2013), Adrião e Garcia (2014), Oliveira (2009), Caetano (2013, 2015), entre outros. No desenvolvimento metodológico, procedemos ao levantamento e à análise de fontes primárias (documentos oficiais, institucionais e relatórios) e secundárias (pesquisas e produções já desenvolvidas sobre o tema), além do aporte teórico de outros autores e pesquisas já realizadas pela autora. Buscamos seguir ainda as contribuições para análise de documentos e textos de Shiroma, Campos e Garcia (2005, p.432). A partir das autoras e do referencial que adotamos, atentaremos para o movimento da política educacional a partir de uma articulação complexa entre o público e o privado.

\section{A privatização da educação pública}

As reformas educacionais em curso no Brasil redefinem as formas de compreender a gestão da educação e da escola introduzindo novos elementos, como as parcerias público-privadas, a gestão por resultados, o voluntariado, a filantropia, a terceirização e, também, o que chamamos de privatização, trazendo implicações à educação e à escola.

Em artigo publicado, Caetano (2015) já apresentava que as tendências à privatização se dão tanto de forma direta, a exoprivatização, quanto indireta, a endoprivatização, conforme Ball e Youdell (2008). A endoprivatização opera por meio da instalação de uma série de ferramentas de mercado no próprio funcionamento da política pública. Um dos exemplos de endoprivatização pode ser a transferência do desenvolvimento curricular, que é um elemento-chave na definição do ensino à iniciativa privada. A endoprivatização também pode estar relacionada com a contratação de outros serviços privados nas escolas públicas, como a formação de professores, gestores, contratação de consultorias educacionais, serviços de avaliação, entre outros.

As diferentes formas de privatização vêm instituindo as reformas educativas de forma global. É sob o modo de produção capitalista que existe uma tendência histórica à superação progressiva das fronteiras nacionais no marco do mercado mundial. Wood (2003, p. 8) destaca que "o capital foi capaz de estender seu alcance econômico para muito além das fronteiras de qualquer nação-Estado". Para a autora, o capital precisa do Estado para manter a ordem. Wood $(2003$, p. 8) destaca que "o capital foi capaz de estender seu alcance econômico para muito além das fronteiras de qualquer naçãoEstado". Para a autora, o capital precisa do Estado para manter a ordem e garantir as condições de acumulação e não há evidência de que o capital global tenha encontrado um instrumento mais eficaz. Portanto, as reformas se tornam um dos meios fundamentais para a privatização da coisa pública. Para tratar da privatização, utilizamos a abordagem de Lima (2013, p. 178-179), que compreende que a privatização pode, 


\begin{abstract}
públicas com estatutos de fundação e regidas pelo direito privado, escolas públicas cuja gestão foi concessionada a privados, financiamento através da captação de alunos e respectivos "chequesensino" pagos pelo Estado, interferência crescente no currículo, na prática pedagógica, na avaliação, etc., por parte de instituições privadas, empresas e fundações, organizações não-governamentais diversas ou do chamado "terceiro setor". Privatização pode, ainda, significar a crescente introdução de modos de gestão considerados típicos das organizações privadas, ideologicamente consideradas mais bem geridas, em busca da "zero-burocracia", mais ágeis e manejáveis em ambientes incertos e turbulentos, centradas na necessidade do cliente ou consumidor, induzindo a competitividade no seu interior através da adoção de mercados internos, ou seja, seguindo os princípios normativos e as prescrições técnico-instrumentais da chamada "Nova Gestão Pública".
\end{abstract}

As tendências à privatização estão tendo maior ou menor influência nos diferentes países e se concretizam de diferentes formas nos sistemas de educação pública. No Brasil, o Relatório sobre Privatização da Educação na América Latina e Caribe (2012) aponta a atuação do terceiro setor e a presença de negócios transnacionais ligados a setores financeiros e privados tradicionais do país (idem, p. 18). Peroni (2013), com a contribuição de pesquisadores na área, aborda as diferentes formas de privatização do público: a filantropia empresarial, o capitalismo social, as redes de políticas globais, as consultorias internacionais e as parcerias público-privadas e o quanto implicam na garantia dos direitos sociais e da democracia (idem, p. 9). Portanto, a educação, como um direito, não pode ser tratada como mercadoria, como querem os reformadores. Contudo, observamos que há uma estreita relação entre as empresas, grupos empresariais nacionais, internacionais e do terceiro setor, na forma de ONGs, institutos e fundações. O número de fundações e institutos criados nos últimos anos no país é considerável. Conforme dados do IBGE (2010), há em torno de 290.692 Fundações Privadas e Associações sem Fins Lucrativos, gerando um aumento de 8,8\% de 2006 a 2010 (CAETANO,2015). Essas organizações da sociedade se apresentam, em muitos casos, como sem fins lucrativos e têm uma ligação direta com os bancos ou institutos ou constituem um braço complementar às grandes corporações. Segundo o relatório, há outras formas de privatização na educação do país, como a venda de livros ou sistemas apostilados, propostas de formação de professores e gestores e desenvolvimento curricular, entre outros (ADRIÃO; GARCIA, 2014); (PERONI, 2014); (CAETANO, 2013).

Nesse novo contexto, as ideias pedagógicas passam a assumir, no próprio discurso, o fracasso da escola pública, apresentado como reflexo da incapacidade do Estado de gerir o bem público. Com isso se justifica, também, no âmbito da educação, a primazia da iniciativa privada regulada pelas leis do mercado (SAVIANI, 2008, p. 428).

\title{
A BNCC e o Movimento pela Base Nacional Comum Curricular
}

O avanço das relações entre o Estado e o mercado de soluções educativas têm contribuído para a redefinição da natureza do próprio Estado (BALL,2014). Para o neoliberalismo, o Estado, ao mesmo tempo que reduz as políticas sociais, é um importante criador de mercados oportunizando novos negócios, e as reformas educacionais passam 
a ter um papel importante nesse mercado. O mercado cresce, partindo das reformas e das novas demandas criadas por elas. As soluções para problemas públicos foram compreendidas pelas empresas privadas, originando um mercado de serviços e produtos educativos, privilegiando soluções privadas.

Surgem os empreendedores de políticas, conforme observa Ball (2014), que incluem capacidade intelectual, conhecimentos de políticas, liderança e habilidade de formação de equipes, contatos e habilidades estratégicas (idem, p.41), tudo isso organizado rapidamente para enfrentar grandes desafios. Junto a isso, os novos filantropos (BALL, 2014) que buscam impactos e resultados dos seus investimentos por meio de resultados mensuráveis e o retorno dos seus investimentos. Nesse contexto, o mercado passa a ser o parâmetro de qualidade para os problemas sociais. Uma das questões fundamentais é a divulgação do pensamento hegemônico, de classe, que esses sujeitos representam e modelos baseados nas reformas internacionais como solução à suposta falta de produtividade da educação brasileira. No caso da BNCC, a base é o Common Core americano, base nacional implementada nos Estados Unidos, que inclui apenas linguagens e matemática, as disciplinas cobradas pelas avaliações internacionais que medem a qualidade da educação ofertada no país.

O Movimento pela Base Nacional Comum (MBNC) se apresentou como um grupo não governamental de profissionais e pesquisadores da educação que atua, desde 2013, para facilitar a construção de uma base de qualidade. Esse movimento foi patrocinado pela Fundação Lemann, em conjunto com outras instituições públicas e privadas, coordenou a construção e vem coordenando a implantação da base. O objetivo, segundo pesquisas que realizamos, é direcionar a política educacional brasileira a partir de um projeto hegemônico para a educação. Em 2013, uma delegação brasileira participou, em caráter de Missão Oficial a convite da Fundação Lemann, do Seminário Internacional "Liderando Reformas Educacionais: Fortalecendo o Brasil para o Século XXI", realizado na Universidade de Yale, nos Estados Unidos, já orientando a direção a ser dada a BNCC. Sucederamse seminários, workshops, congressos, audiências públicas financiadas por instituições privadas participantes do MPB sobre a reforma e o currículo. Importante destacar quem são os sujeitos coletivos públicos e privados que fazem parte do Movimento.

Em relação ao Movimento pela Base, os sujeitos vão se movimentando, trocando de lugares e outros sujeitos vão se incorporando. A formação atual não é a mesma que iniciou o MPB em 2013, novos sujeitos foram se integrando a ele. Atualmente, o movimento apresenta a seguinte estrutura: Pessoas, Conselho Consultivo e Apoio Institucional (MPB,2018). Na Figura 1, apresentamos as instituições formadas por institutos, fundações, braços de instituições privadas e bancos. No item pessoas, apresentamos os sujeitos e a instituição que representa. 
Figura 1 - Quem são os sujeitos do MPB

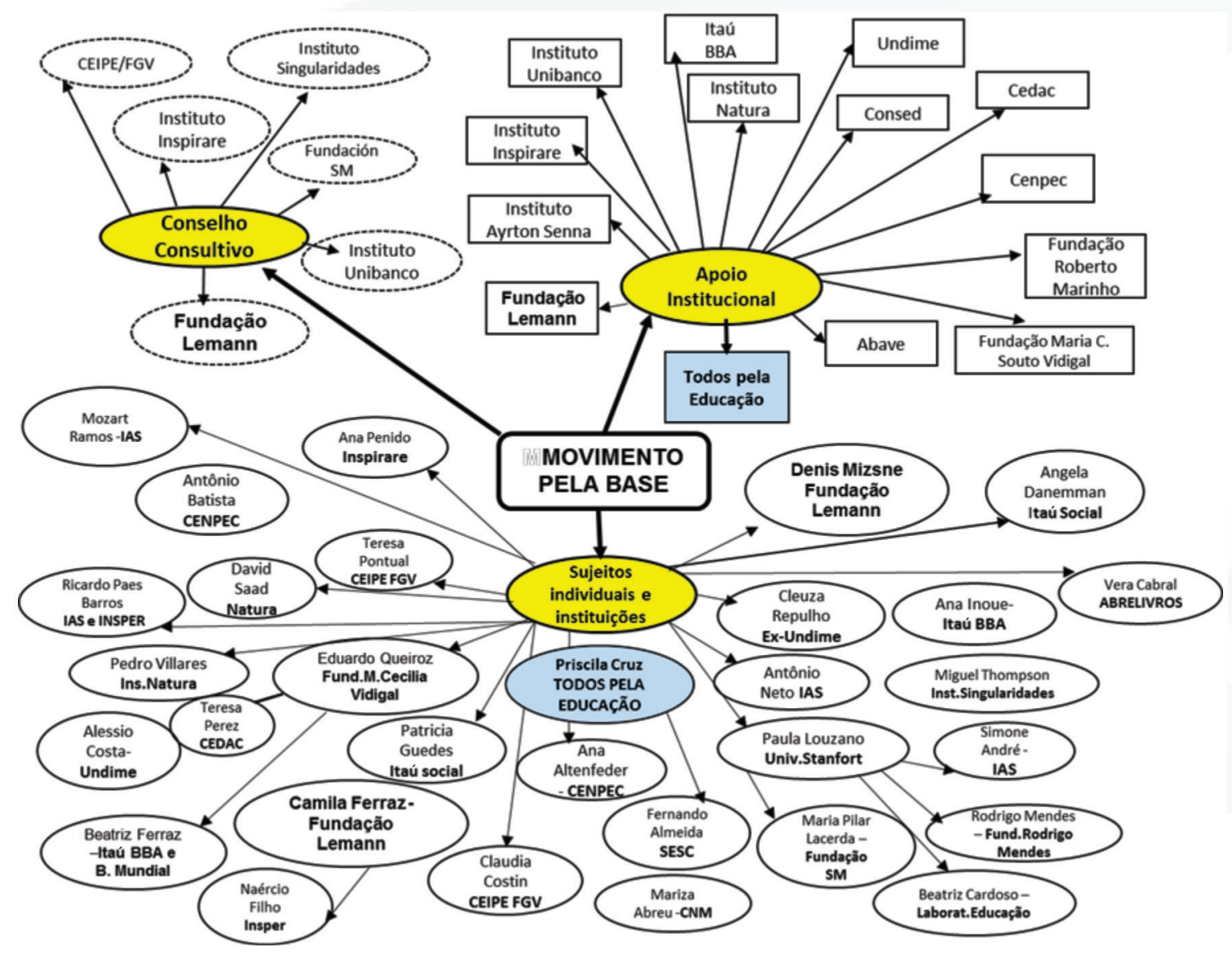

Fonte: Elaborada por Caetano, a partir do MPB (setembro, 2018).

Conforme a Figura 1, podemos ver o protagonismo de instituições ligadas ao empresariado nacional, inclusive com relações a redes internacionais em países sulamericanos e fora dele, embora se intitulem terceiro setor. Ganham destaque a Fundação Lemann, Instituto Ayrton Senna, Instituto Unibanco, Fundação Roberto Marinho, Instituto Inspirare, Fundação Santillana, Abrelivros, entre outros. Essas instituições têm em comum as relações com o organismo Todos pela Educação, um think thank para a educação ligado à rede latino-americana Reduca ${ }^{1}$.

Os sujeitos individuais que fazem parte do MPB desde a sua fundação estão ora no Estado e ora no mercado. As instituições que aparecem na Figura 1 oferecem todo tipo de soluções para a educação pública e lançam no mercado todo tipo de material especialmente destinado à rede pública, da Educação Infantil ao Ensino Médio: programas, livros didáticos, softwares, manuais, plataformas digitais, formação de professores, incluindo contratação de consultores para todo tipo de serviços na educação.

Atualmente, o grupo que compõe o Movimento, segundo ele mesmo, é formado por pessoas e instituições que atuam na área de educação. Muitos estão ou estiveram ligados a Undime, Consed, CNE, MEC. Outros, estavam inicialmente no movimento e alçaram postos no MEC, como é o caso de Katia Smole, ligada ao grupo Mathema, 
que estava na primeira formação do MPB; ou Maria Helena Castro, que foi secretária executiva do MEC na gestão FHC e Temer e faz parte da Associação Brasileira de Avaliação Educacional (Abave), que integra o Conselho Institucional do MPB. Ou, ao contrário, estiveram em funções públicas e hoje estão no privado, como é o caso de Ricardo Henriques, que foi Secretário de Educação Continuada, Alfabetização e Diversidade do MEC (2004-2007) no governo Lula e hoje integra o Instituto Unibanco; Ricardo Paes de Barros, que foi Secretário da Secretaria de Assuntos Estratégicos da Presidência da República (2011/2015) no governo Dilma Rousseff e hoje está no Instituto Ayrton Senna e no Insper; ou Maria Pilar Lacerda, que foi Secretária de Educação Básica do Ministério da Educação de 2007 a 2012 e hoje atua na Fundação SM ligada à Santillana. Essas relações entre público e privado são muito tênues, quando tratamos de políticas educacionais no atual momento histórico, político e social.

A capacidade de articulação é o ponto forte do Movimento pela Base. As organizações ligadas ao empresariado têm atuado na educação pública por meio de diversos programas, conforme já apresentamos. A União Nacional dos Dirigentes Municipais de Educação (Undime) e o Conselho Nacional dos Secretários de Educação (Consed) representam os gestores da educação no Movimento, que conta também com a participação de parlamentares, como Alex Canziani e Thiago Peixoto. As organizações prestadoras de serviços também participam do Movimento. É o caso do Centro de Estudos, Pesquisas, Educação, Cultura e Ação Comunitária (Cenpec), da Comunidade Educativa Cedac e do Laboratório de Educação, todas financiadas por grandes grupos econômicos, como Itaú Unibanco, Bradesco, Santander, Votorantim e Carioca Engenharia (ANTUNES, 2018).

Para o MEC, a BNCC será a referência para a formação de professores, adequação de livros e recursos didáticos, alinhamento nas avaliações e será utilizada para provimento de infraestrutura escolar, ou seja, é a espinha dorsal da reforma da educação. Com a BNCC, o governo pretende sucatear a educação pública, a fim de privatizá-la de todas as formas possíveis, e veem consolidando o projeto de submeter a educação escolar às prerrogativas do mercado, como já apresentamos. $O$ formato da Base, que lista objetivos de aprendizagem, já serviria como controle para as avaliações em larga escala. Em entrevista a André Antunes (2018, p.5), Camila Rostirola diz que "a BNCC vai ter relação com as matrizes de referência das avaliações nacionais e, posteriormente, das avaliações estaduais, justamente para garantir que as escolas sigam ela à risca".

Salomão Ximenes, professor da UFABC, contribui dizendo que o interesse das instituições privadas em relação à BNCC

\footnotetext{
... dá ao mercado educacional previsibilidade e segurança econômica. Esse mercado passa a contar com uma definição do conteúdo educacional a ser ofertado a cada ano, a cada semana e, com isso, vai poder formatar o seu sistema de ensino, as suas apostilas, o seu sistema de formação de professores de acordo com isso. (ANTUNES, 2018, p.7).
} 
A implantação da Base vai permitir que os programas sejam direcionados à melhoria de resultados nas avaliações externas, como o Índice da Educação Básica (IDEB). Nesse caso há possibilidade de contratação direta entre municípios e empresas e sistemas que oferecem serviços educacionais como melhorar o IDEB (ANTUNES, 2018), por exemplo, com serviços de venda de todo o tipo de produtos educacionais e a transferência da gestão da escola para OSs (organizações sociais e terceirização da gestão das escolas), cujo foco é a gestão para resultados nas avaliações.

A disputa de projetos não ocorre apenas na oferta da educação e na gestão dos sistemas educacionais municipais, estaduais e federal, mas no controle do conteúdo, dos livros didáticos, da avaliação, dos professores e suas manifestações no cotidiano escolar. Como outro exemplo de influência no conteúdo educacional, podemos citar o Instituto Ayrton Senna, que incidiu sobre as competências socioemocionais; a Fundação Lemann por meio da Revista Nova Escola e Gestão Escolar, que dissemina para as escolas e professores os planos de aulas já alinhados com a BNCC e a sugestão de conteúdos educacionais que as escolas devem implementar; entre outros.

Para o MEC, a BNCC é a espinha dorsal da reforma da educação. No que pese nossas pesquisas, a BNCC se inscreve em um projeto de sucateamento da educação com o objetivo de privatizá-la por dentro e por fora, atendendo aos interesses do capital.

\section{Considerações finais}

As reformas em curso têm mostrado uma íntima relação entre o setor público e privado. A Base Nacional Comum Curricular foi construída pelo Movimento pela Base, cujos sujeitos fazem parte da base empresarial brasileira. Embora seja uma política pública de Estado, a opção pelo diálogo não foi com os professores e alunos, e sim com o empresariado. O Movimento pela Base orientou desde o início a construção da BNCC e agora coordena sua implantação. Esse grupo vem influenciando e disputando o conteúdo da proposta educacional brasileira. A disputa não ocorre apenas na oferta da educação e na gestão dos sistemas educacionais municipais, estaduais e federal, mas querem controlar, imediatamente, o conteúdo, os livros didáticos, a avaliação, os professores e as suas manifestações no cotidiano. As instituições do terceiro setor, as quais chamamos de mercantil, passam a assumir um papel preponderante com o estabelecimento de bases políticas e sociais para legitimar projetos que se inscrevem na agenda de atualização política e econômica. Para operacionalizar essa estratégia, iniciativas como legitimar o terceiro setor mercantil e a responsabilidade social empresarial são postas em movimento, resultando na organização de empresários orientados para as questões sociais. Com essa perspectiva, organizações privadas sem fins lucrativos se apresentam como sujeitos individuais e coletivos capazes de intervir na educação do país. Elas advogam a necessidade do fortalecimento de suas instituições para provimento de serviços de interesse público. 
Os empreendedores de políticas e os filantropos no Brasil já vinham utilizando os sistemas públicos como laboratórios para seus projetos, mas ganharam força a partir das relações que estabeleceram como em uma rede para se apoiar. Foi o momento oportuno para que pudessem, por meio do Estado, tentar implantar um projeto hegemônico, de classe, para a educação. Nesse sentido, a defesa da educação pública com gestão e conteúdo público deve ser prioridade na agenda nacional.

\section{Referências}

ADRIÃO, T.; GARCIA, T. Subsídio Público ao Setor Privado: reflexões sobre a gestão da escola pública no Brasil. Revista Políticas Educativas, v.7, p.110-112, 2014.

ADRIÃO, T. Escolas charters nos EUA: contradições de uma tendência proposta para o Brasil e suas implicações para a oferta da educação pública. Educação e Filosofia. Uberlândia, v. 28, n. especial, p. 263-282, 2014.

ANTUNES, A. A quem interessa a BNCC? EPSJV/Fiocruz. Atualizado em 24/10/2018 12h42. Disponivel em http://www.epsjv.fiocruz.br/noticias/reportagem/a-quem-interessa-a-bncc. Acesso: 18 nv.2018.

ANTUNES, R.; ALVES, G. As mutações no mundo do trabalho na era da mundialização do capital. Rev. Educação \& Sociedade, Campinas, v. 25, n. 87, p. 335-351, 2004.

BALL, S. J. Educação Global S.A. Novas redes políticas e o imaginário neoliberal. Ponta Grossa, UEPG, 2014.

BALL, S. J.; OLMEDO, A. A Nova Filantropia, o Capitalismo Social e as Redes de Políticas Globais em Educação. In: PERONI, V. M. V. (Org.). Redefinições das Fronteiras entre o Público e o Privado: implicações para a democratização da educação. Brasília: Líber Livro, 2013. P. 3347.

BALL, S.; JUNEMANN, C. Networks, New Governance and Education. Bristol: Policy Press, 2012.

BRASIL. Base Nacional Comum Curricular. Brasília, 2017. Disponível em: http:// basenacionalcomum.mec.gov.br. Acesso: 30 jun.2018.

BRASIL. Câmara dos Deputados. Comissão de Educação. Relatório de Atividades 2013. Brasília, janeiro de 2013.

CAETANO, M. R. A educação no contexto de crise do capital e as relações entre Estado, mercado e terceiro setor nas políticas educacionais. Laplage em Revista, v. 4, p. 153-168, 2018.

Ensino Médio no Brasil e privatização do público: o caso do Instituto Unibanco. Universidade e Sociedade, Brasília, v. XXIV, p. 84-99, 2015.

A educação foi ao mercado. O mercado como orientador da política de ensino médio no Brasil. In: Anais do $1^{\circ}$ Seminário Nacional Redefinições das fronteiras entre o público e o privado: Implicações para a democratização da educação. Porto Alegre: UFRGS, 2017. v. 1. p. $13-18$. 
Redes Globais e Educação: A rede latino-americana da sociedade civil para a educaçãoREDUCA. In: GLAPP, G.; GLAPP, L. (Org.). Políticas públicas na educação brasileira: desafios emergentes. 1ed.Curitiba: Athena, 2017, v. 1, p. 258-271.

FRIGOTTO, G. A Produtividade da Escola Improdutiva. São Paulo: Cortez,1996.

MOVIMENTO PELA BASE. Quem somos. Disponível em: http://movimentopelabase.org.br/ quem-somos. /Acesso: 30 jun.2018.

OLIVEIRA, R. P. de. A transformação da educação em mercadoria no Brasil. Educação e Sociedade. Campinas, vol. 30, n. 108, p. 739-760, out. 2009.

PERONI, V. M. V. (Org.). Redefinições das fronteiras entre o público e o privado: implicações para a democratização da educação. Brasília: Liber Livro, 2013.

As Implicações da relação público-privada para a democratização da educação no Brasil. Tese (promoção a Professor Titular da Carreira do Magistério Superior), UFRGS. 2016.

PERONI, V. M. V.; CAETANO, M. R.; LIMA, P. de. Reformas educacionais de hoje. In: Revista Retratos da Escola, As implicações para a democracia . Revista Retratos da Escola, Brasília, $\mathrm{v}$. 11, n. 21, p. 415-432, jul./dez. 2017. Disponível em:

$<$ http//www.esforce.org.br>.

PERONI. V. M. V:; CAETANO, M. R. O público e o privado na educação Projetos em disputa? Revista Retratos da Escola, Brasília, v. 9, n. 17, p. 337-352, jul./dez. 2015.Disponível em: http:// retratosdaescola.emnuvens.com.br/rde/article/viewFile/584/658. Acesso: 22 abr.2018.

RAVITCH, D. Vida e Morte do Grande Sistema Escolar Americano: como os testes padronizados e o modelo de mercado ameaçam a Educação. Porto Alegre, Sulina, 2011, 318p.

SAVIANI, D. História das ideias pedagógicas no Brasil. Campinas: Autores Associados, 2008.

Artigo recebido em: 03/12/2018

Aprovado em: 21/03/2019

\section{Contato para correspondência:}

Maria Raquel Caetano. E-mail: caetanoraquel2013@gmail.com

1 A Rede Latino-americana de Organizações da Sociedade Civil para a Educação (REDUCA) - formada por organizações sociais de 15 países latino-americanos, muitas dessas dirigidas por grandes empresários que não mantêm ligações com a área educacional e sim com o setor privado. Ver Caetano (2017). 